\title{
Impact of climatic factors on genetic diversity of Stipa breviflora populations in Inner Mongolia
}

\author{
Q. Zhang', J.M. Niü ${ }^{1,2}$, S.B. Wu ${ }^{3}$, A. Buyantuyev ${ }^{2}$ and J.J. Dong ${ }^{1}$ \\ ${ }^{1}$ College of Life Sciences, Inner Mongolia University, Hohhot, China \\ ${ }^{2}$ Sino-US Centre for Conservation, Energy, and Sustainability Science, \\ Inner Mongolia University, Hohhot, China \\ ${ }^{3}$ School of Environmental and Rural Science, University of New England, \\ Armidale NSW, Australia \\ Corresponding author: J.M. Niu \\ E-mail: jmniu2005@163.com
}

Genet. Mol. Res. 11 (3): 2081-2093 (2012)

Received January 9, 2012

Accepted July 6, 2012

Published August 6, 2012

DOI http://dx.doi.org/10.4238/2012.August.6.12

ABSTRACT. Genetic diversity of Stipa breviflora populations in the Inner Mongolian grasslands of China and its possible correlation with climatic factors was examined using geographic information systems and random amplified polymorphism DNA analysis. A total of 308 bands were produced with 28 arbitrary decamer oligonucleotide. Three major findings were demonstrated. First, the genetic diversity of $S$. breviflora was high but lower than that of Stipa grandis and Stipa krylovii. Second, genetic distances between the populations analyzed using the unweighted pair group method and the Mantel test had a highly positive correlation with geographical distances, indicating that spatial separation of this species in the studied area produced genetic shift in the population. Finally, both canonical correspondence and Pearson's analyses revealed strong correlations between genetic differentiation and temperature in the area. We therefore conclude that temperature variations play an important role in genetic differentiations among the investigated $S$. breviflora populations.

Key words: Stipa breviflora; Random amplified polymorphic DNA; Geographic information system; Genetic diversity; Climatic factors 


\section{INTRODUCTION}

The Eurasian Steppe extends over $8000 \mathrm{~km}$ from northeastern China and Mongolia to Russia, Ukraine, and Hungary. Stipa spp are among the most conspicuous plant species throughout this large geographic area (Coupland, 1993). They constitute zonal vegetation in the Inner Mongolia grassland in the far east of the Eurasian Steppe, where distribution is regulated by temperature and precipitation (Inner Mongolia-Ningxia Joint Inspection Group of Chinese Sciences of Academy, 1985). The important perennial tussock grass, Stipa breviflora, is a common desert steppe species of central Asia. This nutrient-rich and drought-resistant grass is favored by grazing animals because of its palatability and availability in the early spring. It is also highly tolerant to grazing. As a result, S. breviflora has become a major forage resource in the desert steppe (Commission Editorial of Inner Mongolia Flora, 1994).

The species is very common in the Inner Mongolia region of China, Mongolia, Russia, Japan, and central Asian countries, where it is found mainly in a continuous zone extending from the southwest to the northeast. This zone stretches from the northwest of Loess Plateau, across the Yinshan Mountains, and to the south of the Inner Mongolia Plateau (Inner Mongolia-Ningxia Joint Inspection Group of Chinese Sciences of Academy, 1985). S. breviflora in this region constitutes a variety of plant populations. The species can co-dominate with Stipa bungeana in the warm-temperate steppe, Stipa klemenzii in the desert steppe, and Stipa krylovii in the moderate-temperate steppe. Consequently, $S$. breviflora is characterized by a wide range of ecological adaptations to the diverse environmental conditions found in the zone. Therefore, the evaluation of genetic diversity of $S$. breviflora populations in relation to climatic factors - mainly temperature and precipitation - is important.

Genetic diversity is a component of biodiversity, which determines species diversity and ecosystem diversity (Millar and Libby, 1991). Genetic differentiation drives genetic diversity (Schaal et al., 1991) and the relationship between genetic differentiation and environmental factors has been a focus of recent studies (Rossetto et al., 2009; Finger et al., 2010; Santos et al., 2010; Martins et al., 2011). Random amplified polymorphic DNA (RAPD) markers can cover the total genome of organisms, including coding and noncoding regions, and reflect differences in the whole genome (Garcia et al., 1998). It has become one of the most popular sequencing techniques (Nybom, 2004), especially when prior sequence information is unavailable, which is the case for the genus Stipa. This type of molecular marker has been used in a variety of studies, including analyses of genetic diversity and genetic differentiation (Torimaru et al., 2003; Freitas et al., 2008; Ali et al., 2011; Cota et al., 2011). RAPD has been previously applied in molecular ecological studies of Stipa (Turuspekov et al., 2002; Zhao et al., 2004a; Wang et al., 2006). We chose to use an RAPD technique as the most appropriate marker system for the examination of genetic diversity of S. breviflora. Spatial variation, population phylogeny, natural selection, and genetic drift can be analyzed by a combination of geographic information system (GIS) technology and molecular marker techniques (Young, 1995). In rice, the combination of hierarchical cluster analysis with GIS has been demonstrated as a useful tool for the accurate visualization of the spatial distribution of existing genetic diversity within a sample of the germplasm in a given geographic area (Parsons et al., 1999). Later studies have extended 
the approach to other species (Adams et al., 2003; Smith et al., 2006). In this study, we examined the genetic diversity of $S$. breviflora populations and the role of climatic factors in explaining this diversity at 8 sites in Inner Mongolia using GIS and RAPD-based fingerprinting techniques. Our findings will have important implications for explaining population differentiation in the species and its adaptation mechanisms. They will also provide useful information for developing efficient strategies for protection and use of $S$. breviflora resources.

\section{MATERIAL AND METHODS}

\section{Study area and plant material collection}

S. breviflora plants used in this study were sampled from 8 natural populations located in the area bounded by the following coordinates: 107.34-113.33 $\mathrm{E}, 39.24-42.48^{\circ} \mathrm{N}$ (Figure 1, Table 1). At each site, 20 individual plants were randomly selected, and their healthy leaves were harvested and stored with silica gel in resealable bags. All plant material was stored at $-20^{\circ} \mathrm{C}$ before analyses.

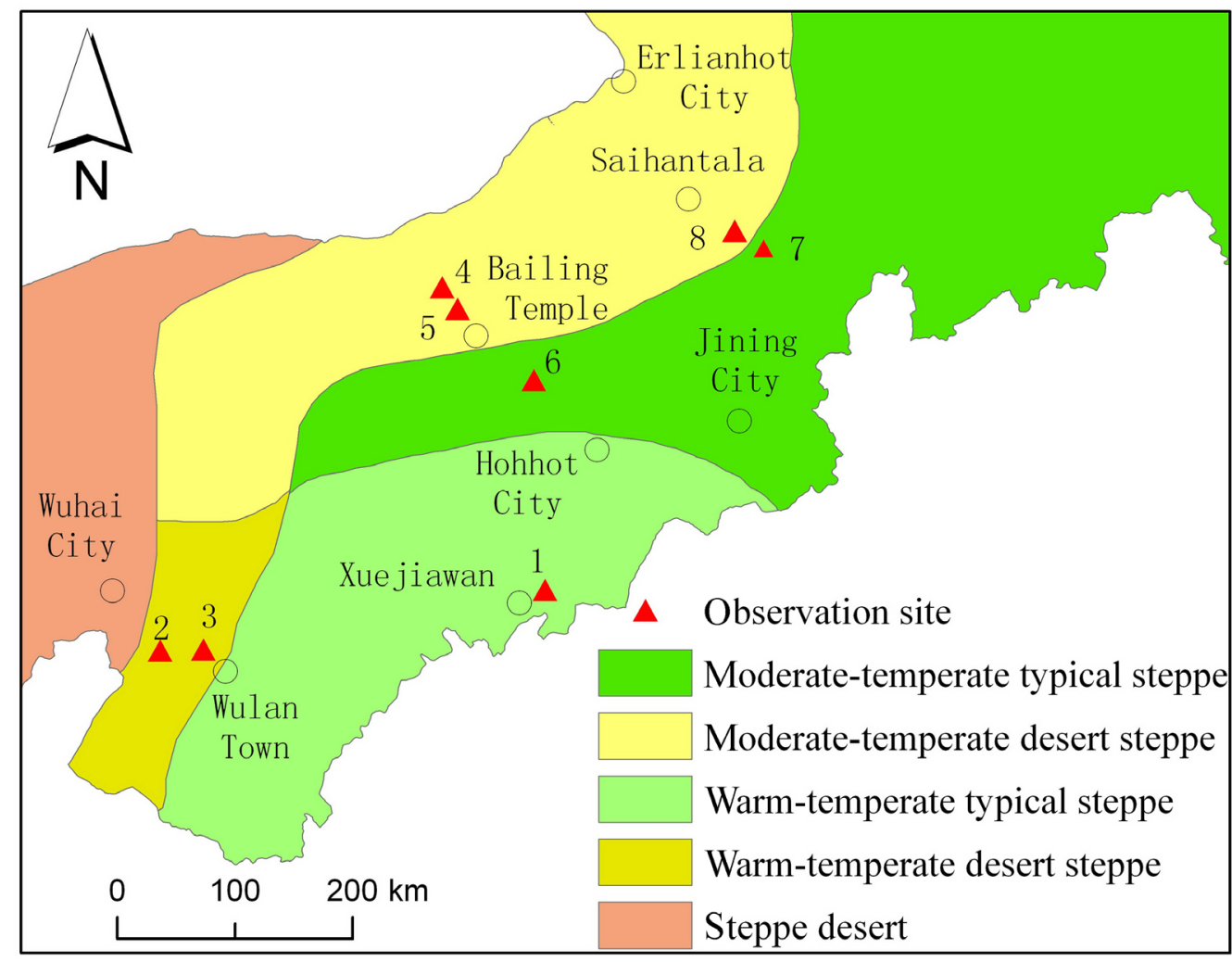

Figure 1. Geographical distribution of 8 populations of Stipa breviflora analyzed in this study. 
Table 1. Characteristics of data collection sites.

\begin{tabular}{|c|c|c|c|c|c|c|}
\hline Administrative area & $\begin{array}{l}\text { Sample } \\
\text { code }\end{array}$ & $\begin{array}{l}\text { Geographic } \\
\text { position }\end{array}$ & $\begin{array}{l}\text { Altitude } \\
(\mathrm{m})\end{array}$ & $\begin{array}{l}\text { Precipitation } \\
(\mathrm{mm})\end{array}$ & Soil types & Vegetation community \\
\hline Junjjar Banner & 1 & $\begin{array}{l}111.13^{\circ} \mathrm{E} \\
39.80^{\circ} \mathrm{N}\end{array}$ & 1129 & 387.3 & Loess & Stipa breviflora and S. bungeana \\
\hline Etuoke Banner & 2 & $\begin{array}{r}107.34^{\circ} \mathrm{E} \\
39.24^{\circ} \mathrm{N}\end{array}$ & 1289 & 264.7 & Light brown calcium & S. breviflora and S. klemenzii \\
\hline Etuoke Banner & 3 & $\begin{array}{r}107.98^{\circ} \mathrm{E} \\
39.26^{\circ} \mathrm{N}\end{array}$ & 1482 & 264.7 & Brown calcium & S. breviflora and Cleistogenes songorica \\
\hline Bayinaobao Town & 4 & $\begin{array}{r}110.12^{\circ} \mathrm{E} \\
41.92^{\circ} \mathrm{N}\end{array}$ & 1426 & 260.9 & Brown calcium & S. breviflora and S. klemenzii \\
\hline Bailing Temple & 5 & $\begin{array}{r}110.37^{\circ} \mathrm{E} \\
41.73^{\circ} \mathrm{N}\end{array}$ & 1388 & 260.9 & Brown calcium & S. breviflora and C. songorica \\
\hline Shibao Town & 6 & $\begin{array}{r}111.02^{\circ} \mathrm{E} \\
41.37^{\circ} \mathrm{N}\end{array}$ & 1682 & 260.9 & Light chestnut calcium & S. breviflora, S. krylovii and Allium polyrhizum \\
\hline Suniteyou Banner & 7 & $\begin{array}{r}113.33^{\circ} \mathrm{E} \\
42.48^{\circ} \mathrm{N}\end{array}$ & 1160 & 217.2 & Light chestnut calcium & S. breviflora and S. krylovii \\
\hline Suniteyou Banner & 8 & $\begin{array}{r}113.25^{\circ} \mathrm{E} \\
42.47^{\circ} \mathrm{N}\end{array}$ & 1175 & 183.0 & Chestnut calcium & S. breviflora, S. klemenzii and A. polyrhizum \\
\hline
\end{tabular}

Annual mean precipitation was calculated for precipitation recorded at weather stations near the sites for the period from 1977 to 2005.

\section{DNA isolation and RAPD analysis}

Leaves harvested from 20 individuals at each site were pooled (equal weights), and the total genomic DNA was extracted using a plant genomic DNA kit (Beijing Tiangen Biotechnology Development Company, China) following manufacturer instructions. DNA concentration and quality were determined using an ultraviolet-visible spectrophotometer under 260 and $280 \mathrm{~nm}$ wavelengths and on $0.8 \%$ agarose gel. DNA was considered of good quality when the ratios of optical densities $260 / 280$ and 260/230 were $\geq 1.8$.

One hundred and two random decamer oligonucleotide primers (Shanghai Sangon Biological Engineering Technology \& Services Company, China) were tested for PCR amplification with 3 aggregated samples, which resulted in the final selection of 28 primers for use in our experiment (Table 2). The protocol for RAPD amplification described previously (Zhao et al., 2004a; Wang et al., 2006) was optimized for S. breviflora as follows. PCR was conducted in a volume of $25 \mu \mathrm{L}$ containing $50 \mathrm{ng}$ DNA, $1 \mathrm{X}$ reaction buffer, $1.5 \mathrm{mM} \mathrm{MgCl}$, $0.2 \mathrm{mM}$ deoxyribonucleotide triphosphates, $0.4 \mu \mathrm{M}$ primer, and $1 \mathrm{U}$ Taq DNA polymerase. The PCR amplification was performed on a Biometra T1 Thermal Cycler (Beijing Huayue Enterprise Holdings Ltd., China) using the following cycling profile: initial 4-min denaturation at $94^{\circ} \mathrm{C}$ followed by 40 cycles of $40 \mathrm{~s}$ at $94^{\circ} \mathrm{C}, 1 \mathrm{~min}$ at $37^{\circ} \mathrm{C}$, and $1.5 \mathrm{~min}$ at $72^{\circ} \mathrm{C}$, and a final extension of $10 \mathrm{~min}$ at $72^{\circ} \mathrm{C}$. Amplification products were analyzed with electrophoresis on $1.5 \%$ agarose gels with DNA marker III (Beijing Tiangen Biotechnology Development Company) as a size standard. The gel was photographed under ultraviolet light after staining with ethidium bromide. The reproducibility and repeatability of the amplification profiles were tested for each primer. Only bands that were clear and consistently reproduced were selected and scored using the Quantity One 4.1.1 program (Bio-Rad Company, USA). RAPD scores were recorded as present (1) or absent (0), and a matrix of RAPD phenotypes was generated and used in the statistical analysis. 
Table 2. The code and sequence of 28 primers used in this study.

\begin{tabular}{llllllll}
\hline Code & Sequence & Code & Sequence & Code & Sequence & Code & Sequence \\
\hline S02 & TGATCCCTGG & S46 & ACCTGAACGG & S157 & CTACTGCCGT & S446 & CCACGGGAAG \\
S03 & CATCCCCCTG & S52 & CACCGTATCC & S318 & GACTAGGTGG & S447 & CAGCACTGAC \\
S19 & ACCCCCGAAG & S126 & GGGAATTCGG & S320 & CCCAGCTAGA & S449 & TCCCACGCAA \\
S27 & GAAACGGGTG & S131 & TTGGTACCCC & S441 & GGCACGTAAG & S450 & TCAGAGCGCC \\
S30 & GTGATCGCAG & S133 & GGCTGCAGAA & S442 & ACGTAGCGTC & S453 & GTCAGAGTCC \\
S32 & TCGGCGATAG & S139 & CCTCTAGACC & S443 & CTGTTGCTAC & S458 & CTCGCTATCC \\
S44 & TCTGGTGAGG & S148 & TCACCACGGT & S444 & AAGTCCGCTC & S460 & ACACACGCTG \\
\hline
\end{tabular}

\section{Climate data}

Ten climatic variables were generated for each site using the following regression models developed previously (Niu, 2001):

$$
\begin{aligned}
& \text { AMT0 }=17974.600-133.910(L A T)-67.929(L N G)-1.471(A L T) \quad\left(\mathrm{R}^{2}=0.96\right) \\
& \text { AMT10 }=18325.700-133.231(L A T)-73.946(L N G)-1.646(A L T) \quad\left(\mathrm{R}^{2}=0.96\right) \\
& \mathrm{CMT}=79.749-1.704(L A T)-0.142(L N G)-0.006(A L T)\left(\mathrm{R}^{2}=0.91\right) \\
& \mathrm{WMT}=83.095-0.395(L A T)-0.334(L N G)-0.007(A L T) \quad\left(\mathrm{R}^{2}=0.93\right) \\
& \mathrm{MT}=82.933-1.029(L A T)-0.248(L N G)-0.007(A L T) \quad\left(\mathrm{R}^{2}=0.96\right) \\
& \mathrm{EVP}=9212.380+4.369(A L T)-0.041(A L T)(L N G)+1487.423(L A T)-17.024\left(L A T^{2}\right) \\
& -625.785(L N G)+2.471\left(L N G^{2}\right) \quad\left(\mathrm{R}^{2}=0.84\right) \\
& \mathrm{P}=13872.124-0.894(A L T)-198.273(L A T)+2.236\left(L A T^{2}\right)-0.031(L A T)(A L T) \\
& -176.057(L N G)+0.830\left(L N G^{2}\right)+0.020(L N G)(A L T) \quad\left(\mathrm{R}^{2}=0.84\right) \\
& \text { P_SF }=11635.218-0.689(A L T)-0.031(A L T)(L A T)+0.018(A L T)(L N G)-141.794(L A T) \\
& +1.623\left(L A T^{2}\right)-158.643(L N G)+0.749\left(L N G^{2}\right) \quad\left(\mathrm{R}^{2}=0.85\right) \\
& P_{-} \text {WS }=6.2789 \mathrm{e}^{\left(0.0501 \times \mathrm{P}_{-} \mathrm{WS} 1\right)} \\
& \text { P_WS1 }=1438.203-0.286(A L T)+1.402\left(A L T^{2}\right) / 100000+0.002(A L T)(L N G)-62.003(L A T) \\
& +0.678\left(L A T^{2}\right) \quad\left(\mathbf{R}^{2}=0.75\right) \\
& \text { FRZ_FD }=1189.464+53.644(L A T)-0.585\left(L A T^{2}\right)-33.533(L N G)+0.142\left(L N G^{2}\right) \\
& -5.495\left(L N G^{2}\right)(A L T) / 1000000-3.93\left(L N G^{2}\right)(L A T) / 10000 \quad\left(\mathrm{R}^{2}=0.82\right)
\end{aligned}
$$

where $L A T, L N G$, and $A L T$ refer to latitude, longitude, and altitude, respectively. AMTO and $A M T 10$ are accumulated air temperatures of $\geq 0^{\circ}$ and $\geq 10^{\circ} \mathrm{C}$, respectively; $C M T$ is the mean temperature of the coldest month (January) and $W M T$ is the mean temperature of the hottest 
month (July); $M T$ is the annual mean temperature; EVP is the annual mean evapotranspiration; $P$ is the annual mean precipitation; $P \_S F$ is the mean precipitation in the summer-autumn; $P_{-} W S$ is the mean precipitation in the spring-winter, and $F R Z_{-} F D$ indicates the annual mean frost-free days.

\section{Statistical analysis of RAPD markers}

Pairwise genetic similarity between all populations was analyzed using a binary data format ( 1 as presence and 0 as absence). The unweighted pair group method with arithmetic mean cluster, which is based on Jaccard's similarity coefficient matrix, was computed using NTSYS-pc 2.01 (Rohlf, 1997). Genetic distance was estimated by subtracting the similarity measure from 1, and geographic distance was extracted using GIS tools and location data collected with the global positioning system. The Mantel test (Mantel, 1967) was performed to evaluate the correlation between population genetic distances and geographic distances using NTSYS-pc 2.01 with 3000 permutations.

\section{Correlation analysis}

The relationships between the molecular markers obtained from 8 populations and 10 climatic factors were explored using the canonical correspondence analysis (CCA) implemented in CANOCO for Windows 4.5 (Ter Braak and Smilauer, 2002). Additionally, Pearson's correlations were examined between the percentages of unique loci in 8 populations and all climatic factors using SPSS 11.0.

\section{RESULTS}

\section{Robustness assessment of pooled RAPD assay}

To assess the robustness of the method, we selected 20 individuals from population 1 and prepared their bulk DNA to test 15 randomly chosen primers (Figure 2). As a result, a total of 162 bands were amplified for all 20 individuals. When the bulk was amplified, we obtained 152 bands (or $94.4 \%$ of the 162 bands obtained from individual amplifications). These 152 bands were represented by 2 types: high-exposure frequency bands $(98.04 \%)$ and low-exposure frequency yet clear bands $(1.96 \%)$. The no-template sample was used to account for cross-contamination of plant material. Because the amplification of the bulk DNA sample by the primers was highly representative of the 20 individuals in the population, bulk DNA samples were used for all of the populations under study.

\section{RAPD polymorphisms and their correlations with geographic distribution}

In total, 308 clear and repeatable bands ranging from 400 to 2000 bp long were amplified by 28 selected primers with an average of 11 bands per primer. One hundred and fifty bands, which constituted $49.03 \%$ of the total, were polymorphic. This percentage translated into an average of 5.4 polymorphic bands per primer. 


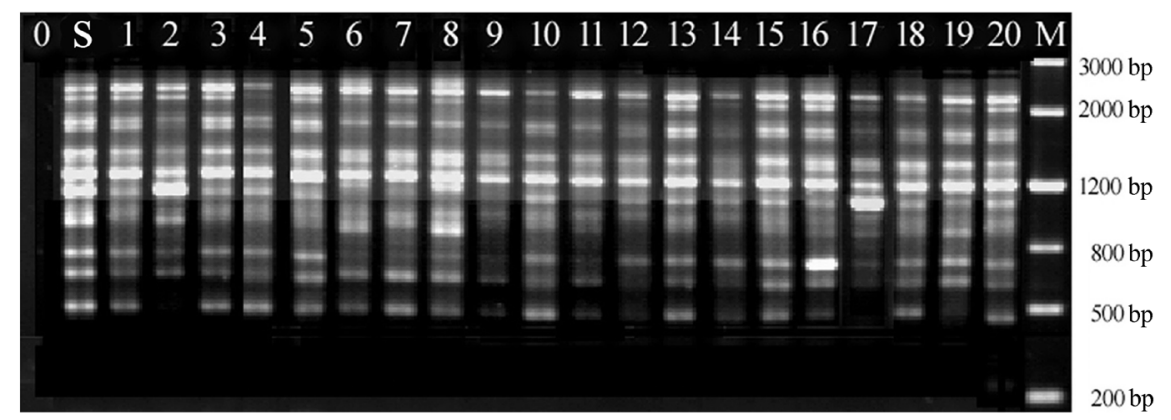

Figure 2. RAPD electrophoretogram of the primer S02. Lanes 1-20 = Selected 20 individuals from population 1; lane $S=$ pooled samples; lane $0=$ no template control; lane $M=$ molecular size standard DNA marker III.

Jaccard's similarity coefficients of genetic distances between populations were calculated and yielded values ranging from 0.316 to $0.582($ mean $=0.460)$. The unweighted pair group method with arithmetic mean dendrogram constructed using these coefficients showed that the 8 populations in this study formed 2 principal clusters corresponding to warm-temperate and moderate-temperate locations (Figure 3). The warm-temperate cluster consisted of 2 subgroups: one occurring in the warm-temperate typical steppe and the other in the warmtemperate desert steppe. The moderate-temperate cluster also consisted of 2 subgroups that were further split into 2 subdivisions each. One subdivision was located in the moderatetemperate typical steppe and the other in the moderate-temperate desert steppe. Such patterns in clustering were highly consistent with the geographic distribution of populations. As Table 3 indicates, the Mantel test also suggested that genetic distance was significantly correlated with geographic distance $(\mathrm{r}=0.534, \mathrm{P}=0.006<0.01, \mathrm{~N}=3000$ permutations $)$.

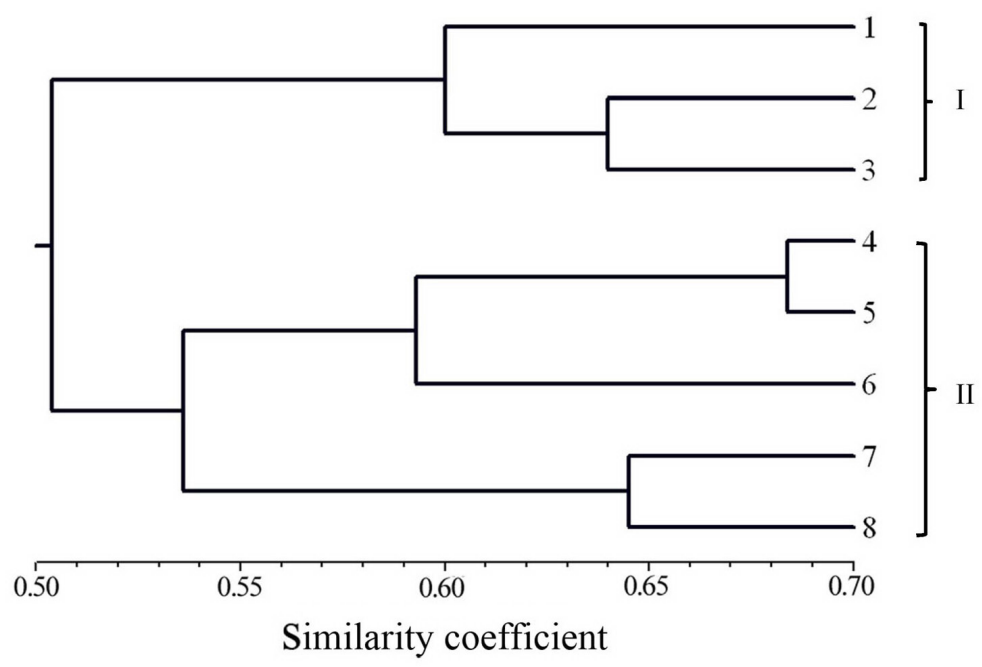

Figure 3. Dendrogram obtained from UPGMA cluster analysis of RAPD data of eight Stipa breviflora populations using Jaccard's similarity coefficients. Cluster I shows the populations located in the warm-temperate sites and cluster II the moderate-temperate sites. The Arabic digits (1-8) are sample codes of the populations. For geographic and climatic information, see Table 1 and Figure 1. 
Table 3. The results of the Mantel test with genetic distance shown above the diagonal and geographic distance $(\mathrm{km})$ below the diagonal.

\begin{tabular}{ccccccccc}
\hline & 1 & 2 & 3 & 4 & 5 & 6 & 7 \\
\hline 1 & $* * * *$ & 0.366 & 0.434 & 0.445 & 0.465 & 0.516 & 0.413 & 0.549 \\
2 & 276.54 & $* * * *$ & 0.360 & 0.496 & 0.539 & 0.582 & 0.459 & 0.560 \\
3 & 331.35 & 55.46 & $* * * *$ & 0.421 & 0.423 & 0.559 & 0.457 & 0.559 \\
4 & 254.83 & 346.76 & 380.42 & $* * * *$ & 0.316 & 0.392 & 0.405 & 0.493 \\
5 & 227.50 & 340.57 & 377.76 & 30.20 & $* * * *$ & 0.422 & 0.370 & 0.523 \\
6 & 178.75 & 348.49 & 392.51 & 97.01 & 67.16 & $* * * *$ & 0.429 & 0.564 \\
7 & 353.95 & 575.13 & 620.23 & 271.93 & 258.49 & 227.84 & $* * *$ & 0.355 \\
8 & 349.87 & 569.50 & 614.44 & 265.51 & 252.15 & 221.99 & 6.45 & $* * * *$ \\
\hline
\end{tabular}

\section{Influence of climatic factors on genetic differentiation of $S$. breviflora}

CCA allows consideration of several environmental factors simultaneously (Ter Braak, 1988) and as such it was used for analyzing relationships between genetic diversity and environmental factors in eight populations of S. breviflora. We found strong correlations between RAPD bands and climatic factors (Table 4). The first 3 ordination axes explained $57.7 \%$ of the total variance in RAPD bands and $73.3 \%$ of the total variance in environmental factors. The MonteCarlo permutation test indicated that all canonical axes were significant $(\mathrm{F}=1.474, \mathrm{P}<0.01,199$ permutations), further supporting the reliability of the CCA results.

Table 4. Results of ordinations produced by canonical correspondence analysis.

\begin{tabular}{lccc}
\hline Axis & 1 & 2 & 3 \\
\hline Eigenvalues & 0.234 & 0.197 & 0.146 \\
Band-environment correlations & 0.998 & 0.983 & 0.999 \\
Cumulative percentage variance of band data & 23.4 & 43.0 & 57.7 \\
Cumulative percentage variance of band-environment relationship & 29.7 & 54.7 & 73.3 \\
\hline
\end{tabular}

Climatic factors that correlated strongly with the first axis were AMT0, AMT10, CMT, WMT, MT, and FRZ_FD (Table 5).

Table 5. Correlations between the first three axes and climatic variables by canonical correspondence analysis.

\begin{tabular}{llcr}
\hline Climatic factor & \multicolumn{3}{c}{ Correlation coefficients } \\
\cline { 2 - 4 } & \multicolumn{1}{c}{ Axis 1 } & Axis 2 & Axis 3 \\
\hline AMT0 & $0.9219^{* *}$ & 0.2843 & 0.0243 \\
AMT10 & $0.9836^{* *}$ & 0.3168 & 0.0220 \\
CMT & $0.9770^{* *}$ & 0.1079 & 0.0963 \\
WMT & $0.8779^{* *}$ & 0.3503 & 0.0004 \\
MT & $0.9598^{* *}$ & 0.1981 & 0.0607 \\
EVP & 0.5770 & -0.5161 & -0.4059 \\
P & 0.4007 & 0.3322 & 0.4301 \\
P_SF & 0.3499 & 0.3647 & 0.4317 \\
P_WS & 0.5808 & -0.0873 & 0.4799 \\
FRZ_FD & $0.8967^{* *}$ & 0.1628 & -0.1646 \\
\hline
\end{tabular}

**Significant at 0.01 levels. AMT0 and AMT10 = accumulated air temperatures of $\geq 0^{\circ}$ and $\geq 10^{\circ} \mathrm{C}$, respectively; $\mathrm{CMT}=$ mean temperature of the coldest month (January); WMT = mean temperature of the hottest month (July); $\mathrm{MT}=$ annual mean temperature; $\mathrm{EVP}=$ annual mean evapotranspiration; $\mathrm{P}=$ annual mean precipitation; $\mathrm{P} S \mathrm{SF}=$ mean precipitation in the summer-autumn; $\mathrm{P}_{-} \mathrm{WS}=$ mean precipitation in the spring-winter; FRZ_FD $=$ annual mean frost-free days. 
Figure 4A demonstrates that populations were clearly separated into 2 groups: the left (4-8) group and the right (1-3) group. The left group included populations from the moderatetemperate steppe and the right group included populations from the warm-temperate steppe. This separation confirms that the differences among populations were caused by temperature differences. Axis 3 illustrates the separation caused by the precipitation differences. The highest separation in climate variables was among P_WS, P_SF, P, and EVP (see Table 5), whereas the highest gradient was found between desert steppe (3 and 5) and typical steppe (1 and 6; Figure 4B). The largest separation of climate variables along axis 2 was attributed to EVP, P_SF, and WMT (see Table 5), demonstrating the combined effects of temperature and precipitation.
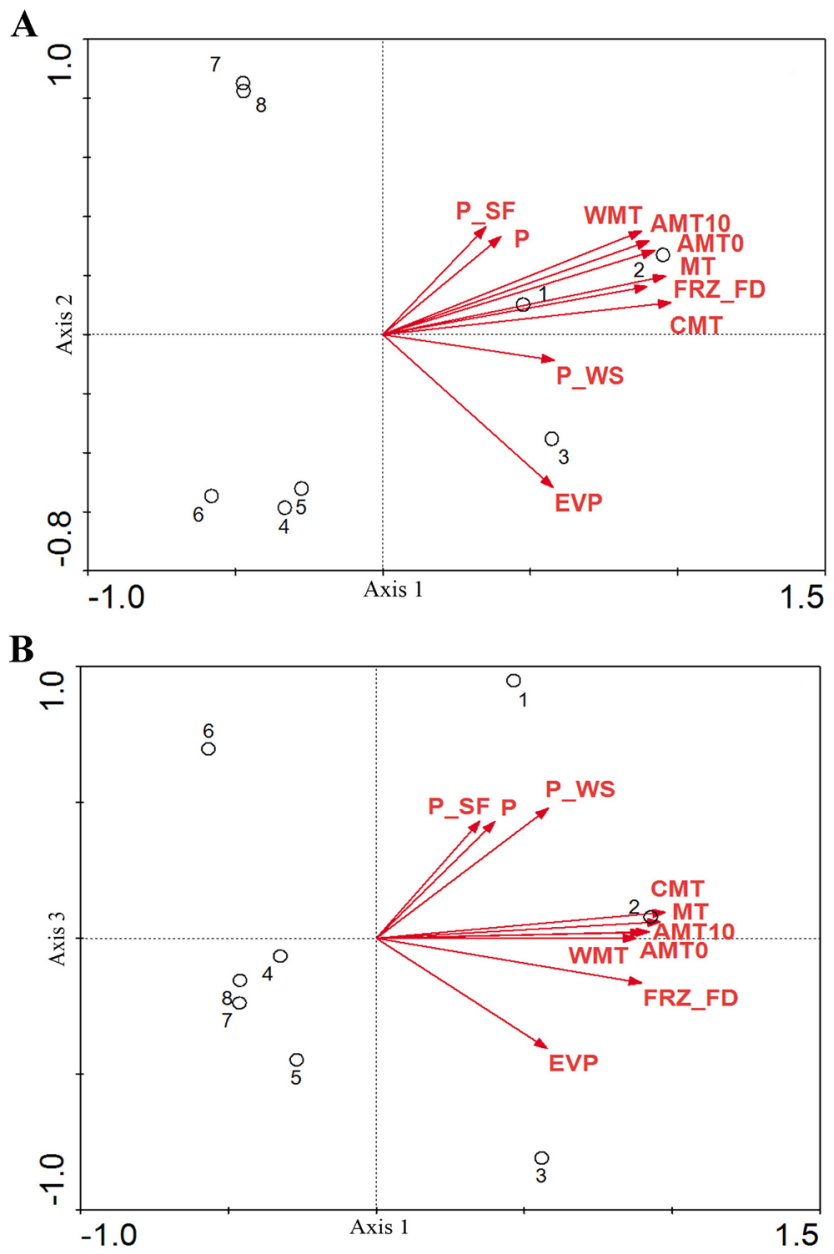

Figure 4. Canonical correspondence analysis of the two-dimensional diagrams of 8 populations and 10 climatic factors: A. along axes 1 and 2; B. along axes 1 and 3. In these two diagrams, the vectors represent climatic factors where length corresponds to the correlation between genetic differentiation and climatic factors. Quadrants indicate the sign of correlations. For abbreviations, see legend to Table 5. 
The total variances explained in the relationships between the bands and climatic factors were $29.4 \%$ for the first axis, $25.0 \%$ for the second axis, and $18.6 \%$ for the third axis. These proportions of explained variance were noticeably low, which was due to excessive noise produced by the presence/absence data (Ter Braak, 1988). Temperature dominated the first axis, whereas a combination of temperature and precipitation dominated the second, and precipitation dominated the third. Therefore, we concluded that temperature variation was the primary climatic factor that determined genetic differentiation in S. breviflora.

\section{Pearson's correlations between percentages of unique loci and climatic factors}

We selected 45 unique loci, or $14.61 \%$, from the total of 308 amplified bands obtained from 8 populations. Correlations between the percentage of unique loci and 10 climatic factors were analyzed using Pearson's correlation (Table 6). The results demonstrated that these variables were uncorrelated when all of the populations were considered. However, significant correlations were found for 6 climate variables (AMT10, AMT0, CMT, WMT, MT, and FRZ_FD) when only 6 populations were analyzed (populations 6 and 8 were omitted).

Table 6. Pearson's correlation between percentage of unique loci and climatic factors.
\begin{tabular}{|lccccccccccc}
\hline Climatic factor & AMT0 & AMT10 & CMT & WMT & MT & EVP & P & P_SF & P_WS & FRZ_FD \\
\hline Coefficient of 8 populations & 0.190 & 0.188 & 0.229 & 0.173 & 0.211 & 0.209 & 0.491 & 0.493 & 0.354 & 0.050 \\
Coefficient of 6 populations & $0.894^{*}$ & $0.887^{*}$ & $0.908^{*}$ & $0.875^{*}$ & $0.906^{*}$ & 0.252 & 0.656 & 0.624 & 0.768 & $0.823^{*}$ \\
\hline
\end{tabular}

*Significant at 0.05 levels. For abbreviations, see legend to Table 5 .

\section{DISCUSSION}

Our study examined genetic diversity of $S$. breviflora populations and its relationships with climatic variables at 8 sites in Inner Mongolia using GIS and RAPD. We found that the genetic diversity of the species was high, correlation between genetic and geographical distances was highly significant, and genetic differentiation correlated strongly with temperature. We concluded that temperature variations play an important role in the genetic differentiations of $S$. breviflora. The methodology that we used has been applied in previous studies (Korol et al., 2007; Eschholz et al., 2008) and shown to be suitable for addressing relationships between genetic spatial variations and climatic factors.

The percentage of polymorphic loci of 8 populations of $S$. breviflora was $49.03 \%$, which is lower than the $54.75 \%$ found for Stipa grandis (Zhao et al., 2004b) and $74.67 \%$ for S. krylovii (Zhao et al., 2004a), which have been analyzed using the same methodology. Such differences are likely due to the highly positive correlation of sexual reproduction of Stipa with moisture levels. The rate of sexual reproduction of the plant has been demonstrated to increases with elevated moisture (Zhang et al., 2005). Because $S$. breviflora tends to grow in drier habitats compared to those of $S$. grandis and $S$. krylovii, we believe that the level of sexual reproduction of $S$. breviflora is lower in the steppe and, hence, reduces genetic variation in the populations. Another factor is the increased anthropogenic stress imposed on the S. breviflora steppe (Sai, 2001), which rapidly undergoes landscape fragmentation leading to diminished genetic flow for the species. 
Percentages of unique loci across populations from the warm-temperate steppe were $>2.50$. They were approximately 2.00 for the moderate-temperate steppe when populations 6 and 8 of the moderate-temperate steppe were omitted from the analysis (see Figure 1; Table 7). No significant correlation between the percentage of unique loci of the 8 populations and 10 climatic factors was detected. However, when populations 6 and 8 were not considered, we found that correlations with AMT10, AMT0, CMT, WMT, MT, and FRZ_FD were significant (see Table 6). These climatic factors describe thermal characteristics of the landscape, so apparently variations in unique loci are directly related to temperature.

Table 7. Percentage of unique loci across 8 populations.
\begin{tabular}{|lcccccccr}
\hline Sample code & 1 & 2 & 3 & 4 & 5 & 6 & 7 & 8 \\
\hline Percentage of unique loci & 2.5751 & 2.8806 & 2.5641 & 1.3216 & 2.1551 & 2.7149 & 1.7857 & 3.7209 \\
\hline
\end{tabular}

Populations 6 and 8 constituted plant communities in which Allium polyrhizum is also found. A symbiotic relationship between S. breviflora and A. polyrhizum has been discovered in which their roots benefit each other in the process of resource acquisition (Zhu, 2003). Therefore, determining whether this relationship is responsible for the substantially high percentage of unique loci in populations 6 and 8 will be important. Additional availability of nutrients facilitates the reproductive process of species from infertile habitats (Chapin, 1980). We speculate that richer mineral or organic nutrient uptake in these 2 populations improves their sexual reproduction, and thus may result in higher genetic diversity in the populations.

Four mechanisms of population genetic differentiation have been suggested (Zhao et al., 2006): 1) genetic flow that includes primarily the dispersal of seed and pollen; 2) natural selection; 3) genetic mutation, which is believed to be a minor mechanism, and 4) genetic drift. Our results from the Mantel test support a considerable genetic flow among $S$. breviflora populations. We hypothesize that successful anemophily of $S$. breviflora is the mechanism responsible for this flow. We believe that genetic drift is not the important mechanism of genetic differentiation of $S$. breviflora because our CCA results revealed significant correlations between genetic differentiation and thermal factors. Previous research, however, suggests that the absence of strong correlations between these variables is evidence that genetic drift is the primary factor of genetic differentiation (Volis et al., 2001).

In conclusion, our study found that genetic differentiation of $S$. breviflora occurs primarily as the result of natural selection in response to temperature spatial variations, whereas genetic flow plays a secondary important role. Similar conclusions have been reached in other studies (Volis et al., 2001; Hall, 2006; Zhao et al., 2006; Eveno et al., 2008). Our findings provide further evidence that climate factors have a direct impact on genetic changes in plant species.

\section{ACKNOWLEDGMENTS}

Research supported by the National Basic Research Program of China (\#31060320), the State Key Basic Research Development Program of China (\#2012CB722201) and the Start Research Funding Project of Inner Mongolia University (\#125106). 


\section{REFERENCES}

Adams JR, Kelly BT and Waits LP (2003). Using faecal DNA sampling and GIS to monitor hybridization between red wolves (Canis rufus) and coyotes (Canis latrans). Mol. Ecol. 12: 2175-2186.

Ali Z, Xu ZL, Zhang DY, He XL, et al. (2011). Molecular diversity analysis of eggplant (Solanum melongena) genetic resources. Genet. Mol. Res. 10: 1141-1155.

Chapin FS (1980). The mineral nutrition of wild plants. Annu. Rev. Ecol. Syst. 11: 233-260.

Commission Editorial of Inner Mongolia Flora (1994). Flora Intramongolia. Inner Mongolia People's Press, Hohhot.

Cota LG, Vieira FA, Melo Júnior AF, Brandão MM, et al. (2011). Genetic diversity of Annona crassiflora (Annonaceae) in northern Minas Gerais State. Genet. Mol. Res. 10: 2172-2180.

Coupland RT (1993). Natural Grasslands: Eastern Hemisphere and Résumé. Elsevier, Amsterdam.

Eschholz TW, Peter R, Stamp P and Hund A (2008). Genetic diversity of Swiss maize (Zea mays L. ssp. mays) assessed with individuals and bulks on agarose gels. Genet. Resour. Crop Evol. 55: 971-983.

Eveno E, Collada C, Guevara MA, Léger V, et al. (2008). Contrasting patterns of selection at Pinus pinaster Ait. drought stress candidate genes as revealed by genetic differentiation analyses. Mol. Biol. Evol. 25: 417-437.

Finger FL, Lannes SD, Schuelter AR, Doege J, et al. (2010). Genetic diversity of Capsicum chinensis (Solanaceae) accessions based on molecular markers and morphological and agronomic traits. Genet. Mol. Res. 9: 1852-1864.

Freitas VL, Lemos-Filho JP and Lovato MB (2008). Contrasting genetic diversity and differentiation of populations of two successional stages in a Neotropical pioneer tree (Eremanthus erythropappus, Asteraceae). Genet. Mol. Res. 7 : 388-398.

Garcia E, Jamilena M, Alvarez JI, Arnedo T, et al. (1998). Genetic relationships among melon breeding lines revealed by RAPD markers and agronomic traits. Theor. Appl. Genet. 96: 878-885.

Hall G (2006). Selective constraint and genetic differentiation in geographically distant barley yellow dwarf virus populations. J. Gen. Virol. 87: 3067-3075.

Inner Mongolia-Ningxia Joint Inspection Group of Chinese Sciences of Academy (1985). Vegetation of Inner Mongolia. Science Publishing House, Beijing.

Korol A, Frenkel Z, Cohen L, Lipkin E, et al. (2007). Fractioned DNA pooling: a new cost-effective strategy for fine mapping of quantitative trait loci. Genetics 176: 2611-2623.

Mantel N (1967). The detection of disease clustering and a generalized regression approach. Cancer Res. 27: 209-220.

Martins K, Chaves LJ, Vencovsky R and Kageyama PY (2011). Genetic structure based on nuclear and chloroplast microsatellite loci of Solanum lycocarpum A. St. Hil. (Solanaceae) in Central Brazil. Genet. Mol. Res. 10: 665-677.

Millar CI and Libby WJ (1991). Strategies for Conserving Clinal, Ecotypic, and Disjunct Population Diversity in Widespread Species. Oxford University Press, New York.

Niu JM (2001). Climate-based digital simulation on spatial distribution of vegetation-A case study in Inner Mongolia. Acta Ecol. Sin. 21: 1064-1071.

Nybom H (2004). Comparison of different nuclear DNA markers for estimating intraspecific genetic diversity in plants. Mol. Ecol. 13: 1143-1155.

Parsons BJ, Newbury HJ and Jackson MT (1999). The genetic structure and conservation of aus, aman and boro rices from Bangladesh. Genet. Resour. Crop Evol. 46: 587-598.

Rohlf FJ (1997). NTSYS-pc: Numerical Taxonomy and Multivariate Analysis System, Version 2.01. Exeter Software, Setauket.

Rossetto M, Crayn D, Ford A, Mellick R, et al. (2009). The influence of environment and life-history traits on the distribution of genes and individuals: a comparative study of 11 rainforest trees. Mol. Ecol. 18: 1422-1438.

Sai SB (2001). Serious desertification of desert steppe zone and its control in northern Inner Mongolia. J. Arid Land Resour. Environ. 15: 34-39.

Santos LM, Gama RA, Eiras AE and Fonseca CG (2010). Genetic differences based on AFLP markers in the mosquito species Anopheles darlingi collected in versus near houses in the region of Porto Velho, RO, Brazil. Genet. Mol. Res. 9: 2254-2262.

Schaal BA, Leverich WJ and Rogstad SH (1991). A Comparison of Methods for Assessing Genetic Variation in Plant Conservation Biology. Oxford University Press, New York.

Smith DA, Ralls K, Hurt A, Adams B, et al. (2006). Assessing reliability of microsatellite genotypes from kit fox faecal samples using genetic and GIS analyses. Mol. Ecol. 15: 387-406.

Ter Braak CJF (1988). CANOCO - an extension of DECORANA to analyze species-environment relationships. Vegetatio 75: $159-160$.

Ter Braak CJF and Smilauer P (2002). CANOCO Reference Manual and User's Guide to Canoco for Windows: Software 
for Canonical Community Ordination (Version 4.5). Microcomputer Power, Ithaca.

Torimaru T, Tomaru N, Nishimura N and Yamamoto S (2003). Clonal diversity and genetic differentiation in Ilex leucoclada M. patches in an old-growth beech forest. Mol. Ecol. 12: 809-818.

Turuspekov Y, Adams RP and Kearney CM (2002). Genetic diversity in three perennial grasses from the Semipalatinsk nuclear testing region of Kazakhstan after long-term radiation exposure. Biochem. Syst. Ecol. 30: 809-817.

Volis S, Yakubov B, Shulgina I and Ward D (2001). Tests for adaptive RAPD variation in population genetic structure of wild barley, Hordeum spontaneum Koch. Biol. J. Linn. Soc. 74: 289-303.

Wang JL, Zhao NX, Gao YB, Lin F, et al. (2006). RAPD analysis of genetic diversity and population genetic structure of Stipa krylovii Reshov. in Inner Mongolia steppe. Genetika 42: 587-594.

Young A (1995). Landscape Structure and Genetic Variation in Plants: Empirical Evidence. In: IALE Studies in Landscape Ecology, Mosaic Landscapes and Ecological Processes (Hansson L, Fahrig L and Merriam G, eds.). Vol. 2. Chapman \& Hall, London, 153-177.

Zhang H, Li X, Jiang FH and Lin GH (2005). Effects of different water supply on the reproduction of Stipa krylovii and Artemisia frigida populations in degraded steppe. Acta Agres. Sin. 13: 106-110.

Zhao NX, Gao YB, Wang JL and Chen L (2004a). A RAPD analysis on genetic differentiation of Stipa krylovii populations in central and eastern Inner Mongolia Steppe. Acta Ecol. Sin. 24: 2178-2185.

Zhao NX, Gao YB, Wang JL, Ren AZ, et al. (2004b). An analysis of genetic differentiation between Stipa grandis populations in middle and eastern Inner Mongolia steppe. Acta Ecol. Sin. 24: 2178-2185.

Zhao NX, Gao YB, Wang JL, Ren AZ, et al. (2006). RAPD diversity of Stipa grandis populations and its relationship with some ecological factors. Acta Ecol. Sin. 26: 1312-1318.

Zhu GL (2003). A new find of relationship between plant populations on Stipa breviflora desert steppe. Acta Bot. Boreal.Occident. Sin. 23: 141-142. 